\title{
PREDATORY BEHAVIOR OF THE BASILICA SPIDER, MECYNOGEA LEMNISCATA (ARANEAE, ARANEIDAE)
}

\author{
BY \\ MarianNe B. Willey ${ }^{1}$ \\ MARGARET A. JOHNSON ${ }^{2}$ \\ AND \\ PETER H. AdLeR ${ }^{1}$ \\ ${ }^{1}$ Department of Entomology \\ 114 Long Hall \\ Clemson University \\ Clemson, South Carolina 29634 \\ ${ }^{2}$ Department of Entomology and Nematology \\ University of Florida \\ Gainesville, Florida 32604
}

\begin{abstract}
Females of Mecynogea lemniscata (Walckenaer) are generalist predators. Sixteen behavioral acts were described for M. lemniscata preying on house flies, carpenter ants, and Asiatic oak weevils in the field and laboratory. Behavioral sequences varied with prey type, but generally began with plucking and diverged thereafter. The predatory behavior of M. lemniscata is most similar to that of the higher araneids.
\end{abstract}

\section{INTRODUCTION}

Mecynogea lemniscata is currently placed in the Araneidae in subfamily Cyrtophorinae (Coddington, 1989), despite having many characteristics in common with linyphiids. Mecynogea has a history of taxonomic uncertainty and has been placed in either the Linyphiidae or the Araneidae by various authorities. Within the Araneidae, Mecynogea has been positioned both as a primitive araneid (Kaston, 1964) and as an advanced araneid (Levi, 1980).

Manuscript received 30 April 1992 
Some of the past uncertainty surrounding the taxonomic placement of Mecynogea is because of the superficial similarity in web structure between Mecynogea and linyphiids; however, web structure is not necessarily a reliable phylogenetic indicator (Levi, 1978). Exline (1948) hypothesized that dome web construction by Mecynogea and Linyphia arose independently through convergent evolution. Similarities between Cyrtophora webs and linyphiid webs also are believed to be the result of convergence (Nentwig and Heimer, 1983; Lubin, 1980), and based on behavior and morphology, Cyrtophora is similar to Araneidae (Blanke, 1972 cited in Lubin, 1980).

The horizontal, domed web of the basilica spider, M. lemniscata (Walckenaer), differs structurally from the more typical, twodimensional, vertical web of most araneids. The permanent spiral is constructed of non-viscid silk pulled into a dome by an array of vertical threads and is enclosed by an irregular barrier web. The web is similar in design to those of Cyrtophora spp. (tropical araneids), and these two genera both construct knockdown traps (Lubin, 1973). This type of web has characteristics of linyphiid webs which are domed and surrounded by vertical suspension threads and theridiid webs which have a loose irregular sheet surrounded by support threads above and sticky trapping threads below. Like linyphiids, M. lemniscata assumes an inverted position beneath the dome.

Because of the unusual structure of the web and the past controversy over taxonomic placement, the behavior of M. lemniscata is of systematic and evolutionary interest. We compare the diet and predatory behavior of M. lemniscata with those of Cyrtophora and some of the well-studied vertical-orb weavers, Argiope, Araneus, and Eriophora, to provide insight into the evolutionary relationship of M. lemniscata. In addition, the predatory behavior is compared to that of Nephila (Tetragnathidae) because of shared web characteristics and past controversy over phylogenetic relationship between the two genera.

Thus, we examined the predatory behavior of M. lemniscata in two steps. First, we examined the natural diet of the spider to determine the predominant prey taxa. We then studied the spider's predatory behavior in response to prey in the three orders most commonly represented in the webs. Predatory behavior was exam- 
ined in the field under natural conditions and in the laboratory under controlled conditions.

\section{Materials ANd Methods}

Study Site

A field population of $M$. lemniscata was studied during the summers of 1986 and 1987 on a $10 \mathrm{~m} \times 30 \mathrm{~m}$ plot along the edge of Lake Hartwell, Clemson, South Carolina. Predominant vegetation consisted of water oak (Quercus nigra L.), choke cherry (Prunus virginiana L.), and green briar (Smilax spp.). Naturally defoliated branches of water oak supported webs of most individuals. During the study, average maximum and minimum daily temperatures at the site were $32.3 \pm 2.9^{\circ} \mathrm{C}$ and $19.9 \pm 2.1^{\circ} \mathrm{C}$ in 1986 and $31.9 \pm 1.6^{\circ} \mathrm{C}$ and $19.3 \pm 2.0^{\circ} \mathrm{C}$ in 1987 . Total rainfall during the study was $2.3 \mathrm{~cm}$ in 1986 and $8.6 \mathrm{~cm}$ in 1987 .

Diet

Diets of randomly chosen adult female spiders were determined by daily collection of prey remains from 22 June through 22 July. Daily sample sizes varied from 6 to 16 spiders (28 individuals total) in 1986 and from 19 to 25 (32 individuals total) in 1987. Sample variation was due to spider mortality and movement. Males of M. lemniscata were not studied due to their web transiency. In 1986, prey remains were collected on $10-\mathrm{cm}^{2}$ fine nylon mesh screens coated with adhesive and strung beneath the webs. In 1987, traps were modified to increase efficiency of prey collection. Each trap consisted of a circular wire frame, $8 \mathrm{~cm}$ in diameter, supporting a paper-lined funnel of fine-mesh cloth. Vials of $80 \%$ ethanol were secured at the tapered end of each funnel.

Each prey item was identified to the lowest feasible taxonomic rank and assigned a value from 0 to 5 based on the amount of silk used to wrap the prey $(0=$ not wrapped, $1=$ prey visible through a thin layer of silk, and $5=$ extensively wrapped with prey not visible through the thick silk). Location of fang insertion was recorded when possible. Body length measurements were taken of intact prey. The presence of web symbionts was recorded. All data are reported as means $\pm \mathrm{SD}$.

Predatory Behavior

In 1986, behavioral tests were performed at the study site during afternoons from 22 July to 5 August. Female spiders with egg sacs 
were chosen randomly from among those included in the prey census. During the 1987 behavioral tests, adult females were collected from near the study site and allowed to build webs freely on metal shelving in an environmental chamber $(4.7 \times 2.4 \times 2.4 \mathrm{~m})$ maintained at $25 \pm 1^{\circ} \mathrm{C}$ and $70 \pm 5 \%$ R.H., with a 14L:10D photoperiod. A sample of 20 spiders without egg sacs was maintained. Each spider was given a maintenance diet of one house fly (Musca domestica L.) per day and was given access to water daily by offering droplets with a syringe. Behavioral observations started three days after beginning the maintenance diet. Spiders were not given a maintenance diet on the day of observations so that each spider fed on only one live insect per day.

In both years, insects offered as prey to spiders $(n=15-17$ spiders per prey taxon) included Asiatic oak weevils (Cyrtepistomus castaneus [Roelofs]), house flies, and workers of a carpenter ant (Camponotus sayi Emery). In the laboratory study, to facilitate capture, one wing was removed from each house fly before presentation to a spider. No spider was tested with more than one prey item per day or on two successive days. A wrap value (0-5) was assigned to each prey item that was consumed or wrapped.

All trials were videotaped at a distance of ca. $1 \mathrm{~m}$. Taping began with the introduction of prey into the upper barrier region of the web and ended when a spider assumed a feeding posture or discarded its prey. Descriptions and sequences of behavioral acts were based on videotape analyses and on direct observations in the field and laboratory. Behavioral acts were transcribed into a firstorder preceding-following transition matrix, and expected values and standard normal deviates were calculated for individual transitions. A binomial test was used to analyze the standard normal deviates to determine which transitions occurred at a frequency greater than that expected by chance (Bishop et al., 1975; Fagen and Young, 1978). Ethograms of significant transitions $(P<0.05)$ were constructed.

Voucher specimens of M. lemniscata, C. castaneus, and C. sayi are deposited in the Clemson University Arthropod Collection. Representative video tapes are also deposited as vouchers. 
RESULTS

Diet

Mecynogea lemniscata fed on insect prey from 11 orders and 83 families. Only one non-insect prey, a single juvenile of Peucetia viridans (Hentz) (Araneae: Oxyopidae), was consumed. Predominant prey consisted of members of the Coleoptera, Diptera, Hymenoptera, and Homoptera (Fig. 1). Formicidae (primarily Crematogaster spp. and Camponotus spp.) was the most numerous taxon, accounting for $11.4 \%$ of all prey in 1986 and $7.9 \%$ in 1987 . Miscellaneous insects were primarily soft-bodied prey, probably Diptera and Psocoptera. Their number was greater in 1987 probably because the small masses of cuticular fragments may have been overlooked on the adhesive traps in 1986.

All prey carcasses were not necessarily consumed by M. lemniscata. Web symbionts, particularly Argyrodes cancellatus (Hentz) (Araneae: Theridiidae), were commonly collected from the webs and may have fed on some prey items. For example, in 1986, one female, six males, and five juveniles of A. cancellatus were collected from eight of 28 webs of M. lemniscata. One female and two males of Tetragnatha elongata Walckenaer (Araneae: Tetragnathidae) were also observed on M. lemniscata webs.

Mecynogea lemniscata handled prey as small as Ceratopogonidae $(1.3 \mathrm{~mm}, \mathrm{n}=3)$, Anthocoridae $(1.4 \mathrm{~mm}, \mathrm{n}=1)$, Cynipidae $(1.5 \mathrm{~mm}, \mathrm{n}=1)$, and Thripidae $(1.6 \mathrm{~mm}, \mathrm{n}=1)$ and as large as Elateridae $(12.5 \mathrm{~mm}, \mathrm{n}=1)$, Coenagrionidae $(13.9 \mathrm{~mm}, \mathrm{n}=1)$, and Chrysopidae $(14.5 \mathrm{~mm}, \mathrm{n}=1)$. Spiders also consumed noxious prey, such as Pentatomidae $(n=4)$, but did not consume the luminous segments of Lampyridae $(n=4)$.

The majority $(75.2 \%[\mathrm{n}=326]$ in 1986 and $66.2 \%[\mathrm{n}=346]$ in 1987) of identifiable prey had been wrapped by the spiders. Wrapping was most extensive for large, powerful prey, such as Curculionidae, Elateridae, Halictidae, and Issidae, and least extensive (little or no silk used) for small, soft-bodied insects, such as Diptera, Chalcidoidea, and Aphididae (Table 1). Not all insects that had been wrapped were eaten. Spiders consumed the contents of $91.5 \%(n=355)$ and $95.6 \%(n=765)$ of prey that we collected in 1986 and 1987, respectively.

As a general rule, heavily sclerotized insects, such as Coleoptera, were fed on through the posterior tip of the abdomen, 

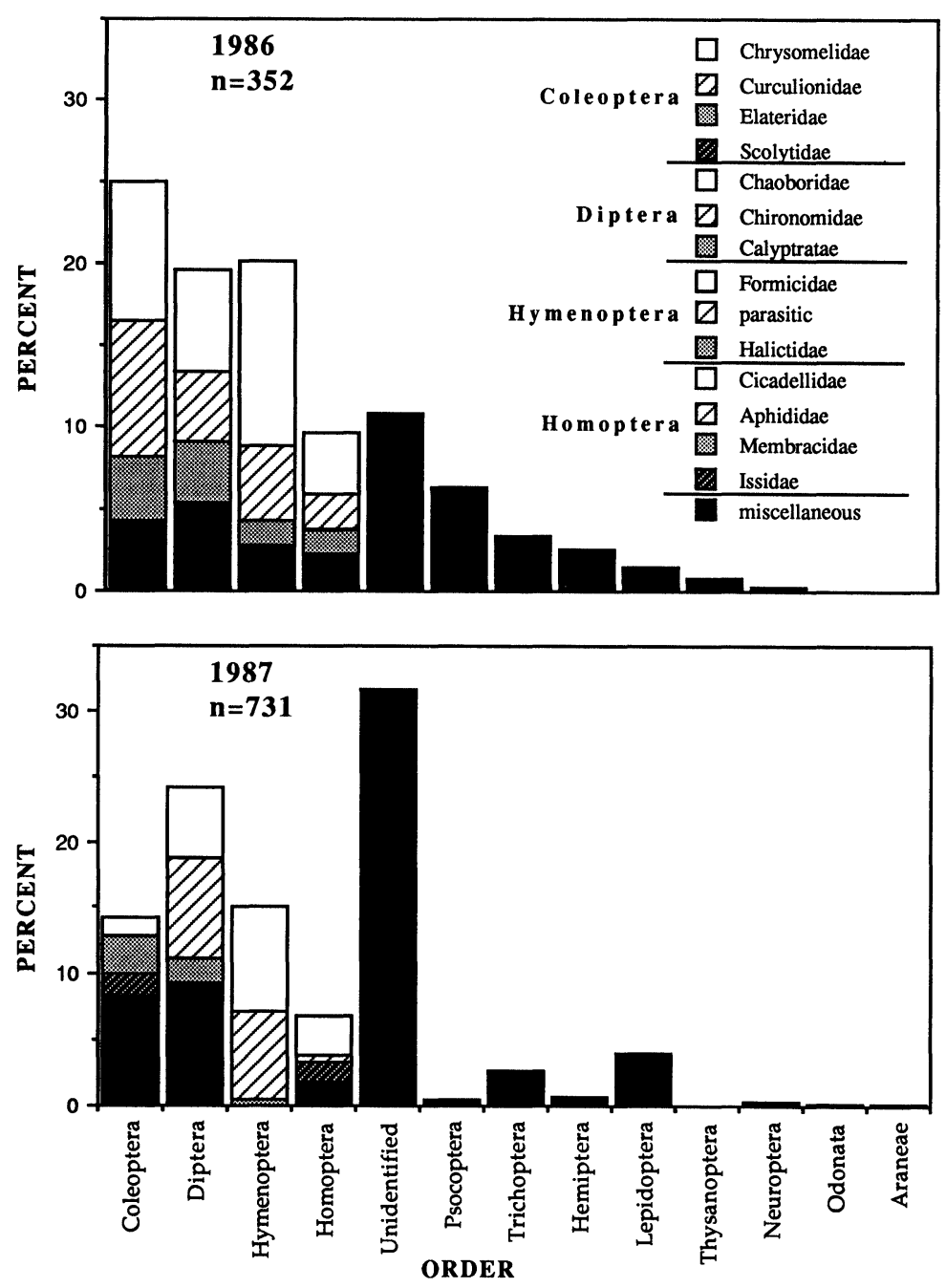

Fig. 1. Prey consumed in the field by M. lemniscata. 
Table 1. Wrap index (mean \pm SD) for dominant prey captured in field webs of $M$. lemniscata.

\begin{tabular}{lrcrr}
\hline \multicolumn{1}{c}{ Taxon } & \multicolumn{2}{c}{1986} & \multicolumn{2}{c}{1987} \\
& $\mathrm{n}$ & wrap & $\mathrm{n}$ & wrap \\
\hline$\quad$ Coleoptera & & & & \\
Chrysomelidae & 32 & $2.7 \pm 1.6$ & 11 & $1.9 \pm 1.4$ \\
$\quad$ Curculionidae & 43 & $4.6 \pm 1.1$ & 7 & $4.7 \pm 0.5$ \\
Elateridae & 14 & $4.6 \pm 0.6$ & 22 & $4.0 \pm 1.2$ \\
Scolytidae & 0 & - & 17 & $2.4 \pm 2.3$ \\
$\quad$ Diptera & 22 & $0.4 \pm 0.7$ & 39 & $0.0 \pm 0.0$ \\
Chaoboridae & 15 & $0.5 \pm 0.8$ & 30 & $0.3 \pm 0.6$ \\
Chironomidae & 11 & $1.2 \pm 1.2$ & 13 & $1.5 \pm 1.4$ \\
Calyptratae & & & & \\
$\quad$ Hymenoptera & 45 & $1.6 \pm 1.6$ & 55 & $2.7 \pm 1.9$ \\
Formicidae & 18 & $2.0 \pm 2.1$ & 28 & $2.2 \pm 2.2$ \\
parasitic* & 7 & $4.1 \pm 1.9$ & 1 & - \\
Halictidae & & & & \\
$\quad$ Homoptera & 14 & $2.0 \pm 1.6$ & 19 & $2.6 \pm 1.2$ \\
Cicadellidae & 9 & $1.8 \pm 1.4$ & 1 & $0.0 \pm 0.0$ \\
Aphididae & 5 & $1.8 \pm 2.2$ & 1 & $0.0 \pm 0.0$ \\
Membracidae & 4 & $3.8 \pm 1.9$ & 14 & $2.7 \pm 1.9$ \\
Issidae & & & & \\
\hline
\end{tabular}

* Braconidae, Chalcidoidea, Proctotrupoidea

whereas soft-bodied insects, such as Diptera, Psocoptera, and Homoptera, usually had fang marks in an eye or the thorax.

Predatory Behavior

Sixteen discrete behavioral acts were identified in the predatory behavior of M. lemniscata (Figs. 2-4).

1.) Pluck. Rapid, longitudinal displacement of web radii with tarsi of legs I and sometimes II (= "jerk" sensu Lubin, 1980), or jerky movement of entire body to shake web; usually a response to prey movement, often as spider orients toward prey.

2.) Bite. Inserting chelicerae while holding prey with legs I-III and grasping web with legs IV. Bites may be single and sustained or repeated, brief, and in multiple locations.

3.) Wrap. Of two types:

a.) Immobilization Wrap. Extensive swathing of prey at capture site, with wide ribbons of silk while using legs I-III or II-III to hold prey. Legs IV, and sometimes I, rest on the web; legs IV 


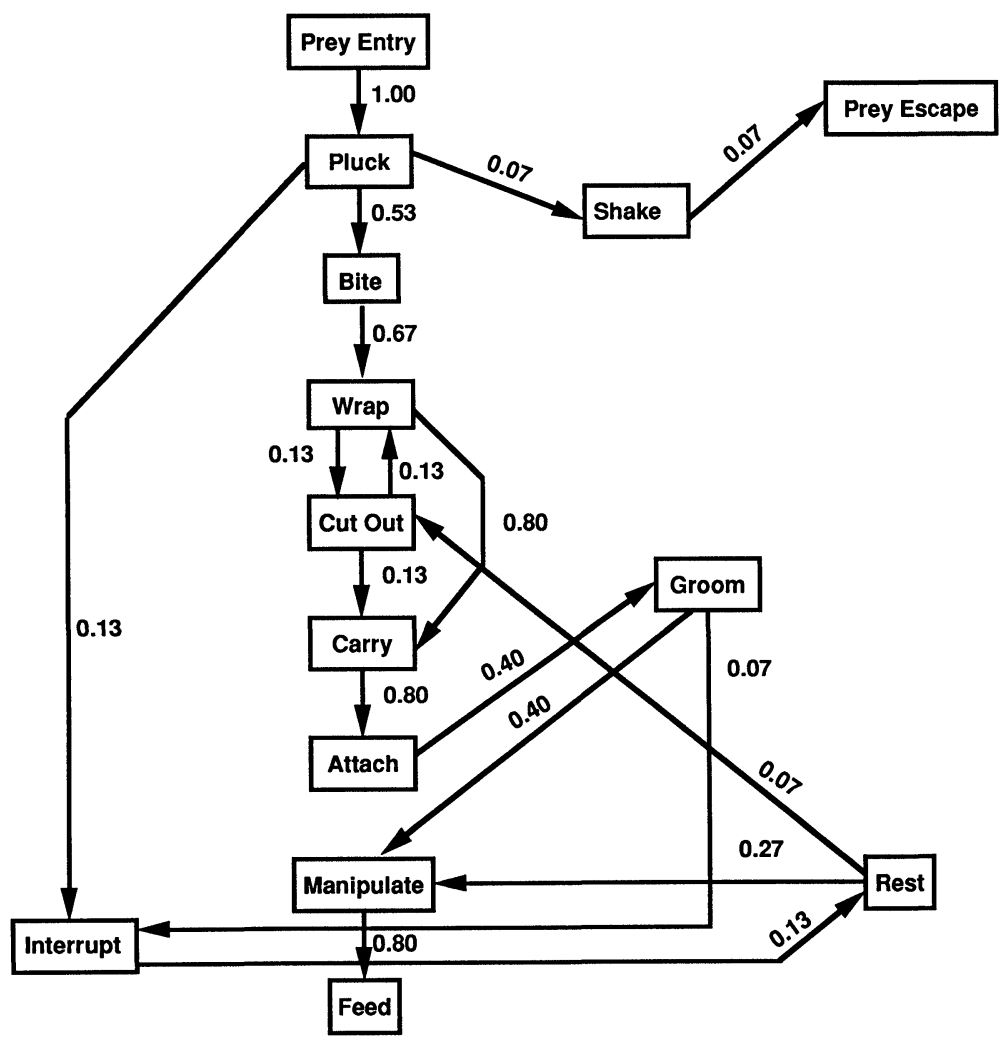

Fig. 2. Field ethogram of predatory acts for $M$. lemniscata, showing significant behavioral transitions $(P<0.05)$ when presented with house flies. Values indicate the frequency of 15 spiders showing a specific transition.

may aid in directing silk. With noxious or retreating prey, spider may throw a broad sheet of silk over web surface and prey (= "throwing" sensu Robinson and Olazarri, 1971), thus enveloping prey.

b.) Postimmobilization Wrap. Less extensive, methodical wrapping at hub where spider rotates prey with legs I-III and applies spinnerets directly to prey (="prey-rotation wrapping" sensu Robinson and Olazarri, 1971). During prey rotation, spider's 


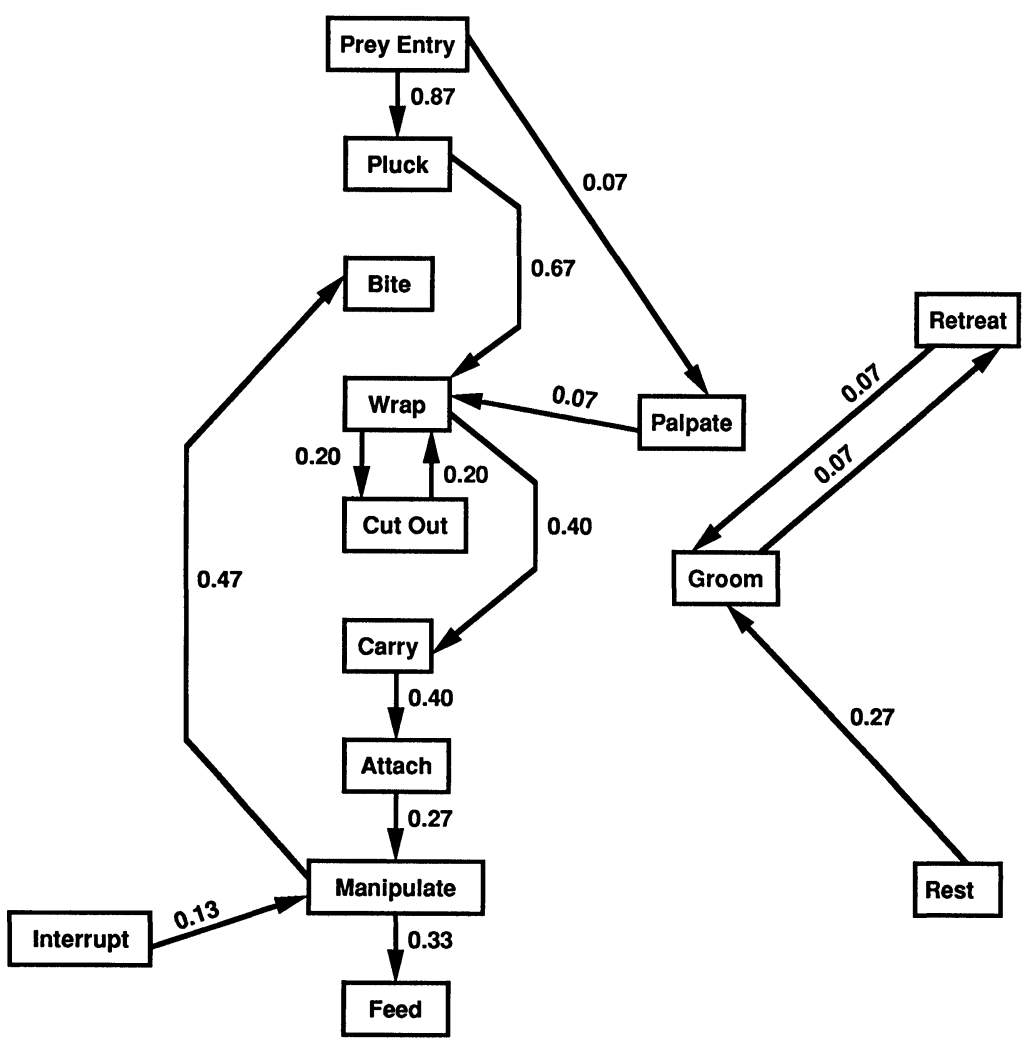

Fig. 3. Field ethogram of predatory acts for M. lemniscata, showing significant behavioral transitions $(P<0.05)$ when presented with carpenter ants. Values indicate the frequency of 15 spiders showing a specific transition.

abdomen moves back and forth distributing silk over the entire body of the prey.

4.) Cut Out. Pedipalps and legs I sever and pull web silk from prey, then chelicerae and legs I remove entangled prey from web.

5.) Carry. Spider carries prey toward hub, either attached to silk strand and carried underneath body with one or both legs IV or carried in jaws. 


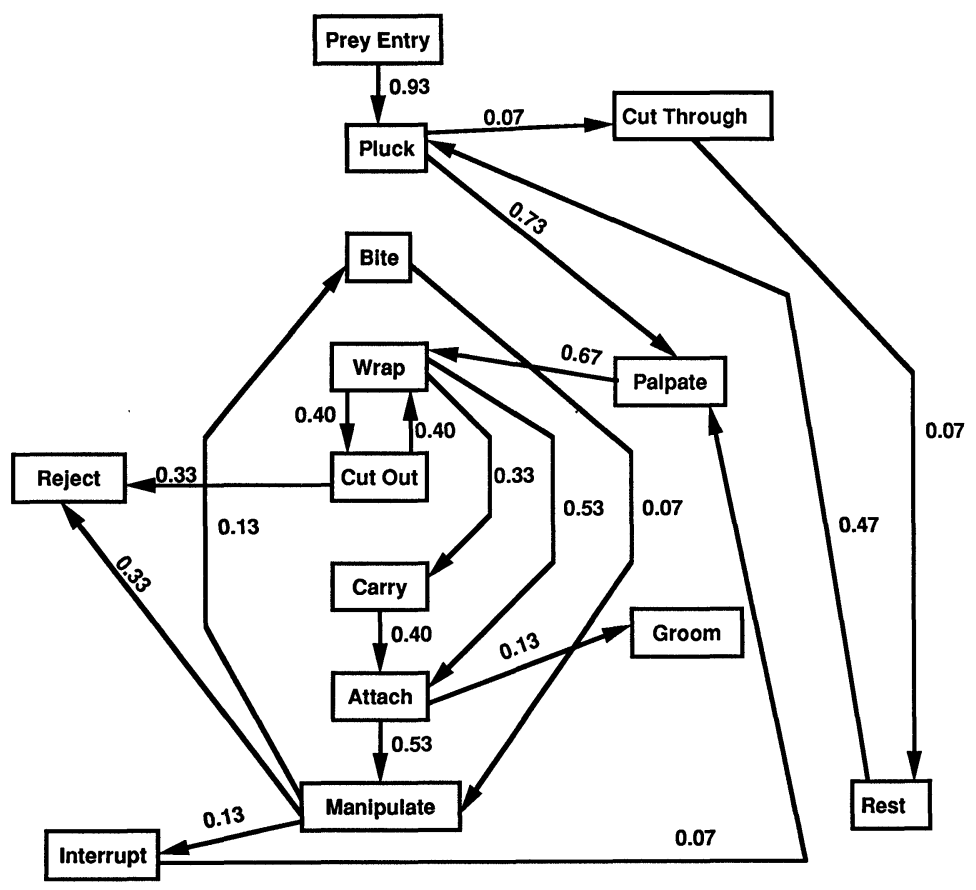

Fig. 4. Field ethogram of predatory acts for M. lemniscata, showing significant behavioral transitions $(P<0.05)$ when presented with Asiatic oak weevils. Values indicate the frequency of 15 spiders showing a specific transition.

6.) Attach. Spider attaches silk to web, often while manipulating prey, with spinnerets, by means of a dabbing motion to secure prey to web surface.

7.) Manipulate. Spider applies several short bites to prey while using pedipalps, legs I-III, and chelicerae to maneuver prey into feeding position.

8). Feed. Spider begins to feed after it plucks or tenses web with legs I-IV. Typical posture involves spider at hub, with legs I-IV on web surface and chelicerae embedded in prey (= "cruciform attitude" sensu Robinson and Olazarri, 1971). 
9.) Interrupt. Defined as any break in predatory behavior caused by natural (e.g., wind, leaves hitting web) or unnatural (observer) disturbances.

10.) Reject. Spider drops prey from web prior to feeding.

11.) Rest. On web with legs I-IV contacting web, generally on hub but sometimes at prey capture site or in retreat. Females with egg sacs may have legs IV in contact with sacs. Alternatively, legs I-III may contact prey while legs IV contact web.

12.) Groom. Legs and palps passed between chelicerae.

13.) Shake. Violent, large amplitude, movements of web surface produced by legs I-II, often in response to prey trapped in barrier web above dome.

14.) Palpate. Pedipalps used to touch prey.

15.) Retreat. Spider moves away from prey to any location on web (usually hub) or drops off web.

16.) Cut Through. Spider severs hub silk with chelicerae and moves to barrier region of web.

Prey Escape. Although a behavioral act of the prey rather than the spider, prey escape is included on the ethograms and occurs when prey struggles free of spider's silk or escapes from the web before spider begins feeding.

The predatory behavior of M. lemniscata varied strikingly in relation to prey types; however, significant behavioral transitions were similar within each prey type, so only field ethograms are presented. All sequences generally began with plucking but diverged thereafter among prey types. With flies (Fig. 2), a bitewrap sequence typically followed plucking, whereas with ants (Fig. 3), wrapping generally followed plucking, and with weevils (Fig. 4), a palpate-wrap sequence followed plucking. The most stable sequence within and among prey types was carry-attach; virtually all carries were followed by attachment of prey.

In the laboratory, spiders consumed $88.2 \%$ of the flies $(n=17)$, $56.2 \%$ of the ants $(n=16)$, and $0 \%$ of the weevils $(n=15)$, although one weevil was consumed after filming ended. In the field, $93.3 \%$ of the flies $(n=15), 60 \%$ of the ants $(n=15)$, and $0 \%$ of the weevils $(n=15)$ were consumed. Of those prey not consumed, all flies, 8 weevils, and all but two ants escaped. Sixteen weevils ( 6 in the laboratory, 10 in the field) were rejected by the spiders. Filming of the remaining 6 weevils and 2 ants was 
discontinued because of long resting periods by the spider. Wrap values for prey presented in the laboratory were $2.2 \pm 0.6$ for flies, $4.1 \pm 0.7$ for ants, and $4.8 \pm 0.4$ for weevils.

\section{DISCUSSION}

Mecynogea lemniscata, like Cyrtophora (Lubin, 1973), appears to be a generalist predator, consuming over $91 \%$ of collected prey. Prey items consumed by M. lemniscata in our study and in Maryland represent a similar taxonomic distribution (Wise and Barata, 1983). Mecynogea lemniscata captured prey similar to that of both araneids and linyphiids (Olive, 1980; Nentwig, 1983). However, prey composition is dependent on the insect fauna located around the web (Nentwig, 1985). Therefore, although linyphiids and araneids differ in prey capture strategies (Nentwig, 1980), prey may be similar (Nentwig, 1983). Apparently, web location, web size, and spider behavior play a greater role in determining diet than does web structure (Wise and Barata, 1983).

Although curculionids were major prey items in the natural diet of $M$. lemniscata, they were rejected when introduced into webs. Tretzel (1961) noted that beetles were the predominant prey item of Coelotes terrestris Wider (Agelenidae) in the field but were rarely accepted in the laboratory. Thus, the primary prey item in nature may not necessarily represent the preferred food (Nentwig, 1983).

Many orb-web spiders exhibit different predatory behaviors in response to different insect prey (Robinson and Olazarri, 1971; Harwood, 1974). Heavily sclerotized weevils elicited extensive manipulation by $M$. lemniscata, probably because the spider was seeking a penetrable location in the cuticle, and frequent thanotaxis elicited pluck, shake, and palpate responses from the spiders. Extensive wrapping probably reduces excessive web damage and probability of escape by struggling prey. Even weevils that had been wrapped extensively were able to free themselves partially (the legs) or entirely. Weevils can escape from Cyrtophora spp. unless immobilized by wrapping (Lubin, 1980).

Rapid movements by ants elicited quick wrapping behavior by M. lemniscata; the formic acid that ants emitted might have been responsible for much of the spider grooming. Immobilization techniques are similar in Cyrtophora spp., with wrapping and frequent 
grooming in response to pentatomids (Lubin, 1980), which produce noxious secretions (Eisner and Meinwald, 1966). By wrapping instead of biting, the spider can avoid the prey's defensive secretions, as evidenced by the fact that Nephila spp.-which only exhibit bite immobilization behavior-are less efficient at attacking noxious hemipterans than are spiders with wrap-immobilization behavior (Robinson and Olazarri, 1971).

On the basis of predatory behavior, Lubin (1980) suggested that Cyrtophora was derived from an advanced araneid ancestor that possessed complex wrapping and biting behavior and evolved minor changes in predatory behavior to adapt to the new type of web. One of these changes, loss of a dragline connection with the hub during prey capture, is seen in Mecynogea and Cyrtophora, but is not present in other araneids (Lubin, 1980). We observed web shaking by M. lemniscata, and shaking of this type among the Araneidae previously has been reported only for Cyrtophora spp. (Lubin, 1980). Web shaking described for other araneids (Argiope and Araneus spp.) and for Nephila (Tetragnathidae) appears to produce higher frequency vibrations and possibly functions as a defensive behavior (Tolbert, 1975). These two shared charactersloss of dragline and web shaking-are possibly synapomorphies for Mecynogea and Cyrtophora.

Although the predatory behavior of the Linyphiidae has not been studied in detail, linyphiids do not immobilize prey by wrapping; therefore, the attack behavior of linyphiids is considered less advanced than that of araneids (Eberhard, 1967). However, various predatory behavioral acts observed in M. lemniscata are similar to predatory acts reported in the following araneid genera (Table 2): Araneus sp. (Peters, 1931, 1933a, 1933b cited in Robinson et al., 1969), Argiope spp. (Robinson, 1969; Robinson et al., 1969; Robinson and Olazarri, 1971), Cyrtophora spp. (Lubin, 1980), Eriophora sp. (Robinson et al., 1969), and in a tetragnathid genus, Nephila spp. (Robinson and Mirick, 1971; Robinson and Robinson 1973). The predatory behavior of M. lemniscata was most similar to Cyrtophora spp. and least similar to Nephila spp., which attack all prey by biting and never by wrapping. Therefore, based on its predatory behavior, we agree with current classification which places M. lemniscata close to Cyrtophora in the Araneidae. Although some of the predatory behaviors were similar to Nephila 
Table 2. Presence (+), absence (-), or uncertainty (?) of major predatory behavioral acts of Mecynogea lemniscata observed in other Araneidae and Tetragnathidae. See text for references.

\begin{tabular}{|c|c|c|c|c|c|}
\hline \multirow{2}{*}{$\begin{array}{c}\text { Predatory Behavioral } \\
\text { Act }\end{array}$} & \multicolumn{5}{|c|}{ Genera } \\
\hline & Araneus & Argiope & Cyrtophora & Eriophora & Nephila \\
\hline Pluck & $?$ & + & + & $?$ & + \\
\hline Bite & $?$ & + & + & + & + \\
\hline Immobilization Wrap & + & + & + & + & - \\
\hline Postimmobilization Wrap & $\mathrm{p}+$ & + & + & + & + \\
\hline Cut Out & $?$ & + & + & + & + \\
\hline Carry & + & + & + & + & + \\
\hline Attach & $?$ & + & + & $?$ & + \\
\hline Manipulate & $?$ & + & + & $?$ & + \\
\hline Rest & $?$ & + & + & $?$ & $?$ \\
\hline Groom & $?$ & + & + & $?$ & + \\
\hline Shake & - & - & + & $?$ & $?$ \\
\hline Palpate & $?$ & + & + & $?$ & + \\
\hline Cut Through & $?$ & $?$ & + & $?$ & $?$ \\
\hline
\end{tabular}

spp., both M. lemniscata and Cyrtophora spp. share more similarities with the higher araneids.

\section{ACKNOWLEDGMENTS}

We thank Robert Bellinger, Jonathan Coddington, Frederick Coyle, Joseph Culin, and Robert Jackson for reviewing this manuscript. This is technical contribution No. 3234 of the South Carolina Agricultural Experiment Station, Clemson University.

\section{Literature Cited}

Bishop, Y. M., S. F. Fienberg, AND P. W. Holland

1975. Discrete multivariate analysis: theory and practice. Massachusetts Institute of Technology Press, Cambridge.

Coddington, J. A.

1989. Spinneret silk spigot morphology: evidence for the monophyly of orbweaving spiders, Cyrtophorinae (Araneidae), and the group Theridiidae plus Nesticidae. J. Arachnol. 17: 71-95.

EBERHARD, W.

1967. Attack behavior of diguetid spiders and the origin of prey wrapping in spiders. Psyche. 74: 173-181. 
EISNER, T. AND J. MEINWALD

1966. Defensive secretions of arthropods. Science. 153: 1341-1350.

EXLINE, H.

1948. Morphology, habits, and systematic position of Allepeira lemniscata (Walckenaer) (Araneida: Argiopidae, Allepeirinae). Annals Entomol. Soc. Am. 41: 309-325.

FAGEN, R. M. AND D. M. YounG

1978. Temporal patterns of behaviors: durations, intervals, latencies, and sequences, pp. 79-114. In P. W. Colgan [ed.], Quantitative ethology, Wiley, New York.

HARWOOD, R. H.

1974. Predatory behavior of Argiope aurantia (Lucas). Am. Midl. Nat. 91: $130-139$.

KASTON, B. J.

1964. The evolution of spider webs. Am. Zool. 4: 191-207.

LEVI, H. W.

1978. Orb-webs and phylogeny of orb-weavers. Symp. Zool. Soc. Lond. 42: $1-15$.

1980. The orb-weaver genus Mecynogea, the subfamily Metinae and the genera Pachygnatha, Glenognatha, and Azilia of the subfamily Tetragnathinae North of Mexico (Araneae: Araneidae). Bull. Mus. Comp. Zool., Cambridge. 149: 1-75.

LUBIN, Y. D.

1973. Web structure and function: the non-adhesive orb-web of Cyrtophora molucccensis (Doleschall) (Araneae: Araneidae). Forma et Functio. 6: 337-358.

1980. The predatory behavior of Cyrtophora (Araneae: Araneidae). J. Arachnol. 8: $159-185$.

NENTWIG, W.

1980. Wie funktionieren Spinnennetze? Biologie in unserer Zeit, Weinheim. 10: 117-119.

1983. The prey of web-building spiders compared with feeding experiments (Araneae: Araneidae, Linyphiidae, Pholcidae, Agelenidae). Oecologia. 56: 132-139.

1985. Prey analysis of four species of tropical orb-weaving spiders (Araneae: Araneidae) and a comparison with araneids of the temperate zone. Oecologia. 66: 580-594.

Nentwig, W. AND ST. Heimer

1983. Orb webs and single-line webs: An economic consequence of space web reduction in spiders. Z. zool. Syst. Evolut.-forsch. 21: 26-37.

Olive, C. W.

1980. Foraging specializations in orb-weaving spiders. Ecology. 61: 1133-1144.

RoBINSON, M. H.

1969. Predatory behavior of Argiope argentata (Fabricius). Am. Zool. 9: 161-173.

Robinson, M. H. AND H. MIRICK

1971. The predatory behavior of the golden-web spider Nephila clavipes (Araneae: Araneidae). Psyche. 78: 123-139. 
ROBINSON, M. H., H. MIRICK, AND O. TURNER

1969. The predatory behavior of some araneid spiders and the origin of immobilization wrapping. Psyche. 76: 487-501.

RoBinson, M. H. AND J. OLAZARRI

1971. Units of behavior and complex sequences in the predatory behavior of Argiope argentata (Fabricius): (Araneae: Araneidae). Smithson. Contrib. Zool. No. 65: 1-36.

RoBinson, M. H. AND B. RoBINSON

1973. Ecology and behavior of the giant wood spider Nephila maculata (Fabricius) in New Guinea. Smithson. Contrib. Zool. 149: 1-76.

TOLBERT, W. W.

1975. Predator avoidance behaviors and web defensive structures in the orb weavers Argiope aurantia and Argiope trifasciata (Araneae: Araneidae). Psyche. 82: 29-52.

TRETZEL, E.

1961. Biologie, ökologie, and brutpflege von Coelotes terrestris (Wider) (Araneae, Agelenidae). Z. Morph. Ökol. Tiere (Berlin). 49: 658-745.

WISE, D. H. AND J. L. BARATA

1983. Prey of two syntopic spiders with different web structures. J. Arachnol. 11: $271-281$. 

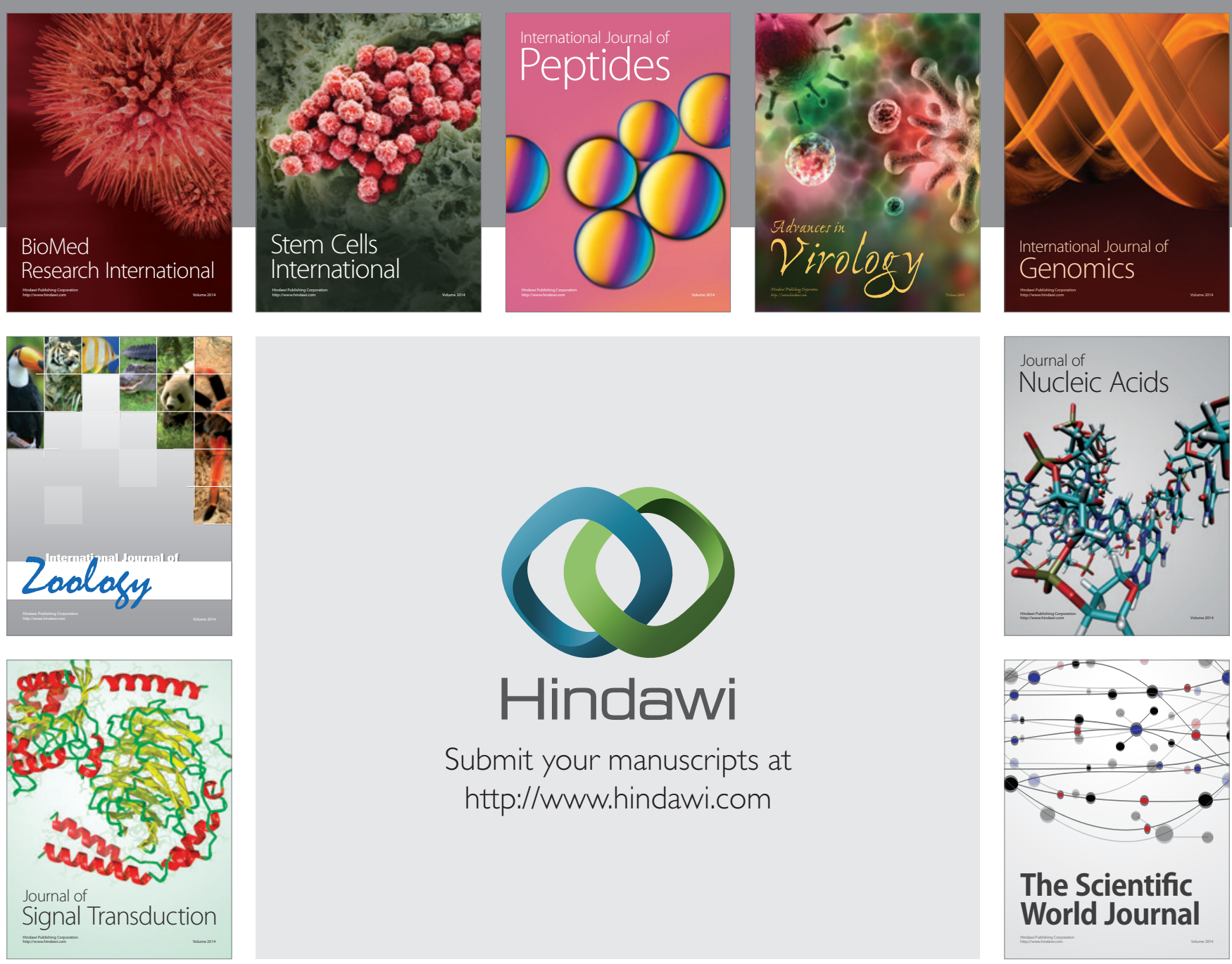

Submit your manuscripts at

http://www.hindawi.com
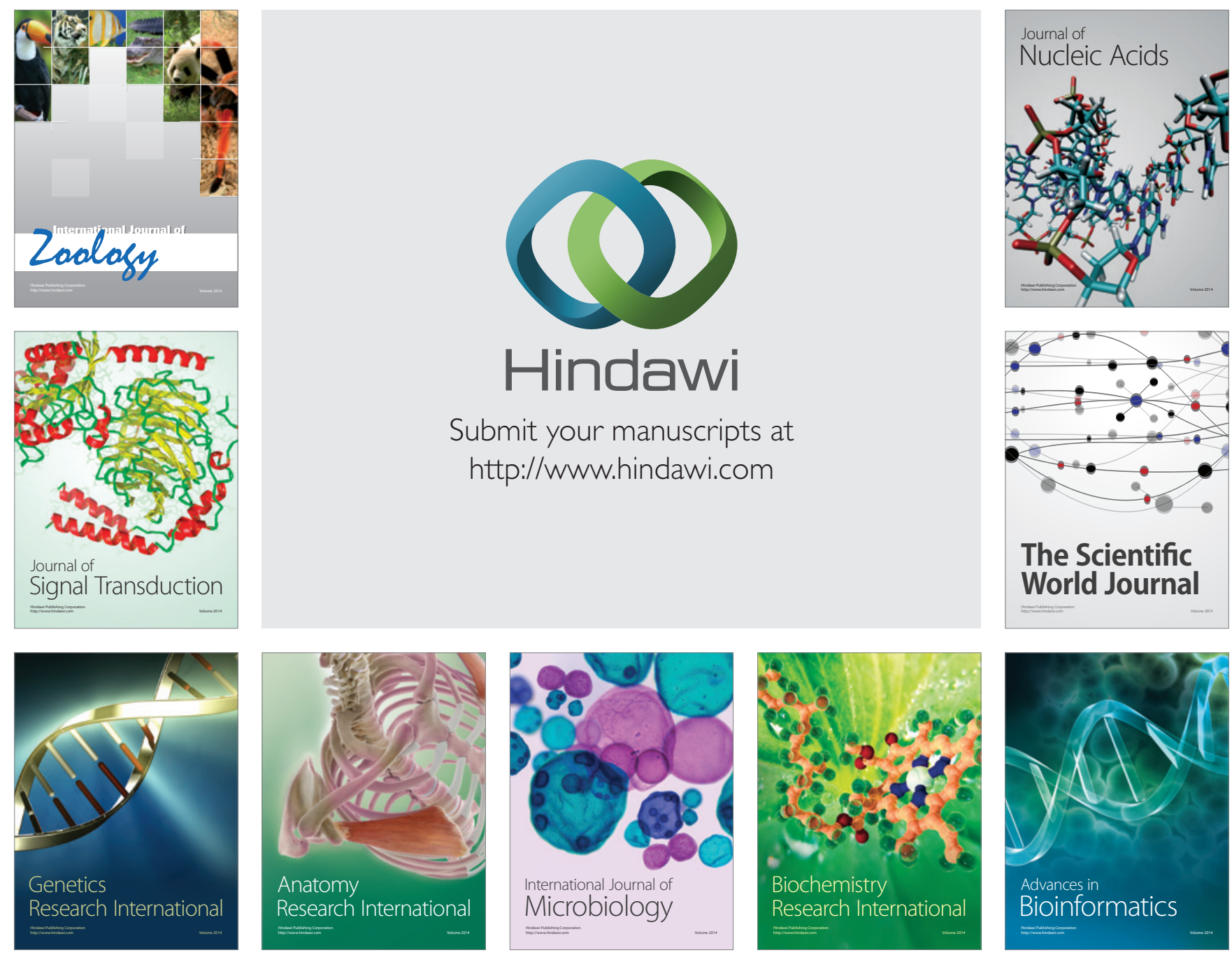

The Scientific World Journal
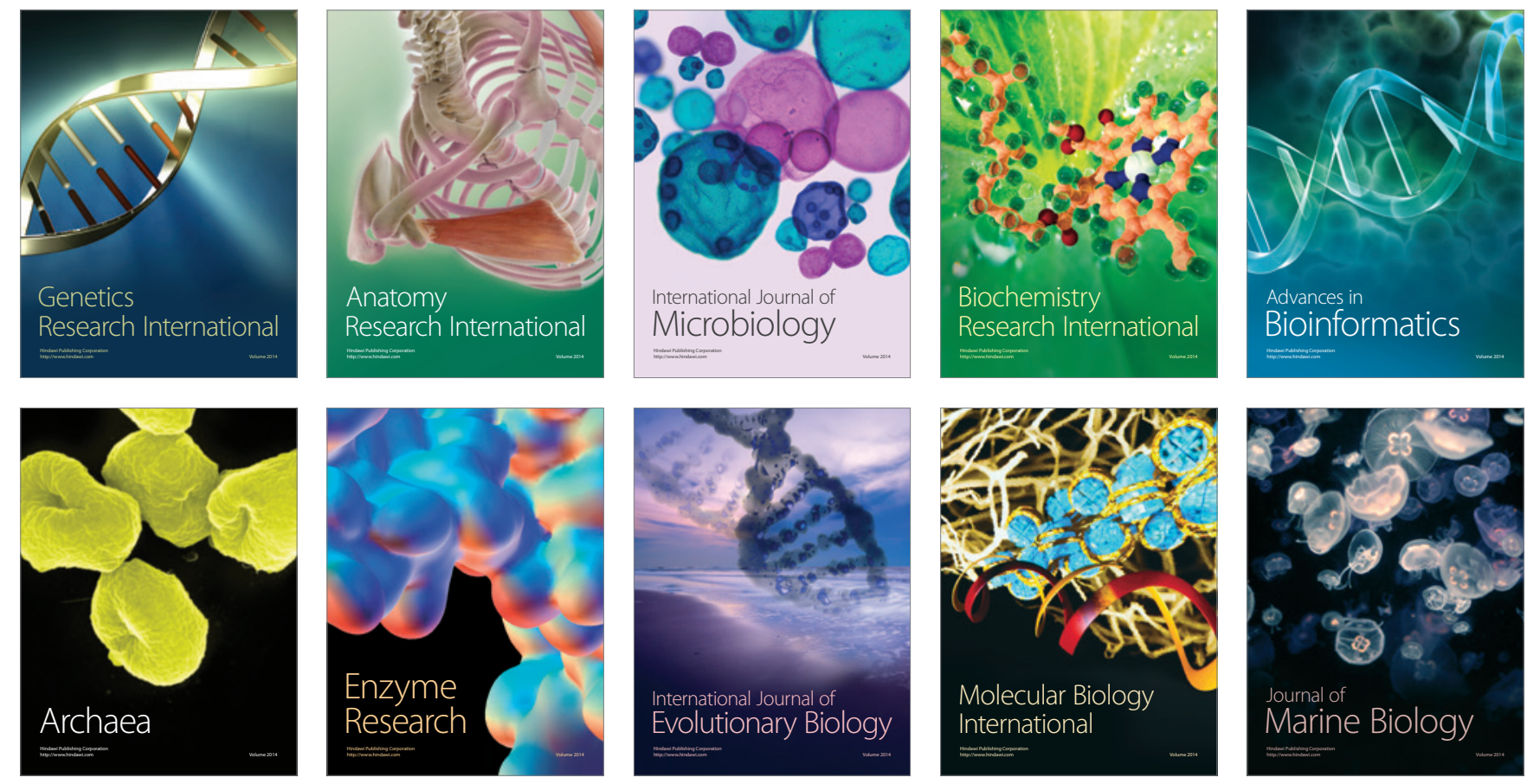